\title{
Dopants and Impurity-Induced Defects in $\mathrm{ZnO}$
}

\author{
M. AZIZAR RAHMAN, MATTHEW R. PHILLIPS \\ and CUONG TON-THAT* \\ School of Mathematical and Physical Sciences, \\ University of Technology Sydney, Ultimo, NSW 2007, Australia \\ *cuong.ton-that@uts.edu.au
}

\begin{abstract}
In recent years, there has been resurgent interest in $\mathrm{ZnO}$ due to its efficient UV emission and potential application in opto-electronic devices. The problem of self-compensating defects, especially those related to acceptor-like dopants, remains a major challenge to date. In this chapter, we provide an overview of the fundamental properties of point defects and dopants as well as their complexes in bulk crystals and nanostructures. Nominally undoped $\mathrm{ZnO}$ is typically n-type, which has been widely ascribed to $\mathrm{O}$ vacancies or $\mathrm{Zn}$ interstitials; however, these defect assignments are controversial as $\mathrm{O}$ vacancies are deep donors while Zn interstitials are highly mobile at room temperature and considered to be unstable. Accordingly, $\mathrm{H}$ and group III impurities have also been suggested to be responsible for the observed n-type conductivity. Although there are still many unanswered questions concerning defect-related luminescence bands in $\mathrm{ZnO}$, great progress has been made in recent years to identify and characterize them using spatially resolved luminescence spectroscopies and first-principles calculations. The ubiquitous green emission has several possible origins, including $\mathrm{O}$ and $\mathrm{Zn}$ vacancies as well as $\mathrm{Cu}$ impurities. The properties of group I ( $\mathrm{Li}, \mathrm{Na}$, and $\mathrm{Cu}$ ), group III ( $\mathrm{Ga}, \mathrm{Al}$,
\end{abstract}




\section{1. Introduction}

5 Zinc oxide is a wide-bandgap semiconductor with great potential for numerous applications such as solid-state lighting [1,2], solar cells [3], lasing [4], and sensors [5]. With a large exciton binding energy of $60 \mathrm{meV}, \mathrm{ZnO}$ emits light efficiently in the UV region of the spectrum, making it a strong candidate for optical devices. In contrast to GaN, large crystals of $\mathrm{ZnO}$ can be grown easily and the low cost of $\mathrm{Zn}$ makes $\mathrm{ZnO}$ economically competitive for large-scale device fabrication. While $\mathrm{ZnO}$ have inherent advantages, the lack of control over native defects and impurities presents a major obstacle to the realization of practical devices. The presence of such defects and impurities can inhibit the performance of devices due to detrimental effects such as nonradiative recombination, carrier trapping, as well as parasitic luminescence and absorption. The literature in this area is vast, and only reasonably well-established results are discussed in this chapter. For readers interested in a complete critical discussion on the structural and physical properties of $\mathrm{ZnO}$ materials and devices, excellent comprehensive review articles have been published by other workers [6-8].

\section{Point Defects in $\mathrm{ZnO}$}

\subsection{Intrinsic point defects}

Several theoretical and experimental studies of defect formation in $\mathrm{ZnO}$ have been reported [6, 9, 10], and the calculated energy levels of different defects as a function of Fermi level position are displayed in Fig. 1. These data show that defects such as $\mathrm{O}$ and $\mathrm{Zn}$ vacancies have lowest formation energies in $\mathrm{Zn}$ - and O-rich $\mathrm{ZnO}$, respectively. Accordingly, $\mathrm{Zn}$ vacancies play a dominant role as compensating acceptors in n-type $\mathrm{ZnO}$. O vacancies are present in significant

and $\mathrm{In}$ ), and group $\mathrm{V}(\mathrm{N}, \mathrm{P}$, and $\mathrm{Sb}$ ) impurities as well as their complexes with native point defects and $\mathrm{H}$ are discussed, along with a concluding outlook for future research into the optical properties of $\mathrm{ZnO}$. 


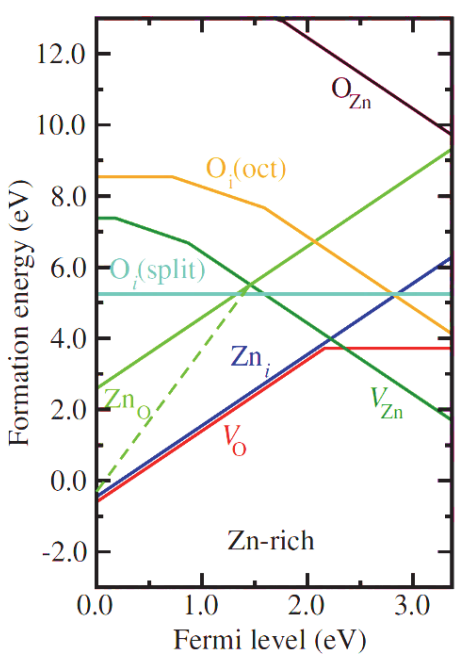

(a)

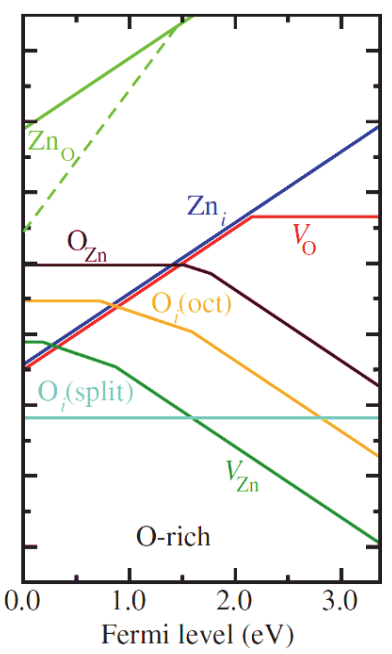

(b)

Figure 1. Calculated formation energies of native defects as a function of Fermi level for (a) Zn-rich and (b) O-rich ZnO. The zero of Fermi-level indicates the valence band maximum and the slope corresponding to the charge states. Positive slopes correspond to positively charged defects, indicating their donor-like behavior. Negative slopes indicate negatively charged defects and acceptor-type behavior. Reprinted with permission from [12].

concentration but unlikely to be the dominant cause of n-type conductivity in nominally undoped $\mathrm{ZnO}$ due to their deep donor nature, while $\mathrm{Zn}$ interstitials are unstable at room temperature due to their high mobility $[11,12]$. Other native point defects including oxygen antisites $\left(\mathrm{O}_{\mathrm{Zn}}\right)$ and zinc antisites $\left(\mathrm{Zn}_{\mathrm{O}}\right)$ are typically not abundant in $\mathrm{ZnO}$ under equilibrium conditions due to their high formation energies; the effect of these defects on the properties of $\left(\mathrm{Zn}_{\mathrm{O}}\right)$ is not discussed further in this chapter. Table 1 provides a summary of the reported energy-level positions of the four main point defects in $\mathrm{ZnO}$ : zinc vacancy $\left(\mathrm{V}_{\mathrm{Zn}}\right)$, oxygen vacancy $\left(\mathrm{V}_{\mathrm{O}}\right)$, zinc interstitial $\left(\mathrm{Zn}_{i}\right)$, and oxygen interstitial $\left(\mathrm{O}_{i}\right)$.

\subsubsection{Oxygen vacancies}

$\mathrm{O}$ vacancies have the lowest formation energy among the native donor-like defects (Fig. 1) and have frequently been cited as the cause 
Table 1. Summary of energy positions of native point defects in different charge states in $\mathrm{ZnO}$.

\begin{tabular}{lccc}
\hline Native defect & Charge state & Energy level $(\mathrm{eV})$ & References \\
\hline$V_{\mathrm{O}}$ & 0 & $E_{c}-0.05$ & {$[25]$} \\
& $1+$ & $E_{c}-2.0, E_{c}-1.92, E_{c}-2.24$ & {$[25-27]$} \\
$\mathrm{Zn}_{i}$ & $2+$ & $E_{c}-1.0, E_{c}-1.1$ & {$[13,19]$} \\
& 0 & $E_{c}-0.05$ & {$[25,26]$} \\
$V_{\mathrm{Zn}}$ & $1+$ & $E_{c}-0.5, E_{c}-0.2$ & {$[25,26]$} \\
& $2+$ & $E_{c}-0.15, E_{c}-0.08$ & {$[14,28]$} \\
& 0 & $E_{v}+0.3, E_{v}+0.31$ & {$[29,30]$} \\
$\mathrm{O}_{i}$ & $1-$ & $E_{v}+0.7, E_{v}+0.82$ & {$[25,26]$} \\
& $2-$ & $E_{v}+2.8, E_{v}+2.91, E_{v}+2.67$ & {$[25,27]$} \\
& 0 & $E_{v}+1.08, E_{v}+0.9$ & {$[29,31]$} \\
& $1-$ & $E_{v}+0.38, E_{v}+0.4$ & {$[31,32]$} \\
& $2-$ & $E_{v}+0.99, E_{v}+1.43 E_{v}+0.79$ & {$[30,32]$} \\
\hline
\end{tabular}

of n-type conductivity in $\mathrm{ZnO}$. However, first-principles calculations show that the $V_{\mathrm{O}}$ is a deep, negative $\mathrm{U}$ donor, where the $1+$ charge state is thermodynamically unstable [6, 12, 13], converting spontaneously to either its $2+$ or 0 charge state. $\mathrm{O}$ vacancies become neutral when the Fermi level is close to the conduction band and above the $V_{\mathrm{O}} 0 / 2+$ charge transition level. Conversely, when the Fermi level is below the $0 / 2+$ level, $V_{\mathrm{O}}$ have a charge of $+2 e$ and can act as a source of compensation in p-type $\mathrm{ZnO}$. The position of the $0 / 2+$ charge transition level for $\mathrm{O}$ vacancies was calculated to be $1-2 \mathrm{eV}$ below the conduction band maximum [14, 15].

A green luminescence band is commonly observed in both bulk and nanostructured $\mathrm{ZnO}$ materials and has been controversially attributed to $\mathrm{O}$ vacancies [16-18]. The difficulty in identifying the origin of this defect band is the fact that it is broad and often overlaps with other broad visible emission peaks, which leads to inaccuracy in the measurement of the green emission peak's position, width, and intensity without the use of careful curve fitting. The reported peak energy of $V_{\mathrm{O}}$-related green luminescence varies from 2.42 to $2.54 \mathrm{eV}$ (Table 2). Ye et al. [19] reported that the radiative recombination of an electron from the $V_{\mathrm{O}}^{+}$state to the valence band is responsible for the 2.5-eV green emission band, whereas Hofmann et al. [20] reported 
Table 2. Summary of energy positions and the proposed defects responsible for deep-level emissions in $\mathrm{ZnO}$.

\begin{tabular}{llcc}
\hline Peak position $(\mathrm{eV})$ & Emission color & $\begin{array}{c}\text { Proposed } \\
\text { defect }\end{array}$ & References \\
\hline $2.2-2.5$ & Green & $V_{\mathrm{o}}$ & {$[16-18,20,43,47]$} \\
$2.3-2.5$ & Green & $V_{\mathrm{Zn}}$ & {$[17,18,47]$} \\
2.4 & Structured green & & {$[48,49]$} \\
$2.7-3.1$ & Blue & & {$[27,35,41]$} \\
1.7 & Red & $\mathrm{O}_{i}$ & {$[50]$} \\
2.3 & Green & & {$[47]$} \\
$2.0-2.1$ & Yellow/Orange & & {$[33,44,51]$} \\
$1.8-2.0$ & Red & $\mathrm{Zn}_{i}$ & {$[40,51,45]$} \\
$2.5-2.7$ & Blue & & {$[41]$} \\
2.85 & Violet & &
\end{tabular}

that the optical excitation can convert only a fraction of $V_{\mathrm{O}}$ to $V_{\mathrm{O}}^{+}$, which is thermodynamically unstable. It is noted that the different energies of the "green" band in different studies could be associated with different defects; we observed two distinct emission bands at 2.30 and $2.52 \mathrm{eV}$, attributable to $\mathrm{Zn}$ and $\mathrm{O}$ vacancies, respectively (see Fig. 2) [18].

\subsubsection{Zinc vacancies}

$\mathrm{Zn}$ vacancies in $\mathrm{ZnO}$ are double acceptors and have a negligible concentration in p-type $\mathrm{ZnO}$ because of their high formation energy. On the contrary, $V_{\mathrm{Zn}}$ has the lowest formation energy among native point defects and is present in a moderate concentration in donordoped $\mathrm{ZnO}$ [12]. These acceptors are more favorable to form in the O-rich environment (Fig. 1). Positron annihilation experiments have confirmed that $Z n$ vacancies are dominant compensating acceptors in n-type $\mathrm{ZnO}$ [21]. Theoretical and experiments results have been reported for the energy level of $V_{\mathrm{Zn}}$ in different charge states (Table 1). In semiconductor terminology, the charge transition level of a defect is defined as the position of Fermi level at which the two charge states of this defect have equal formation energies. Firstprinciples calculations reported the $0 / 1-$ and $1-/ 2-$ acceptor charge transition levels of $V_{\mathrm{Zn}}$ at $0.18-0.2 \mathrm{eV}$ and $0.87-1.2 \mathrm{eV}$ above the 


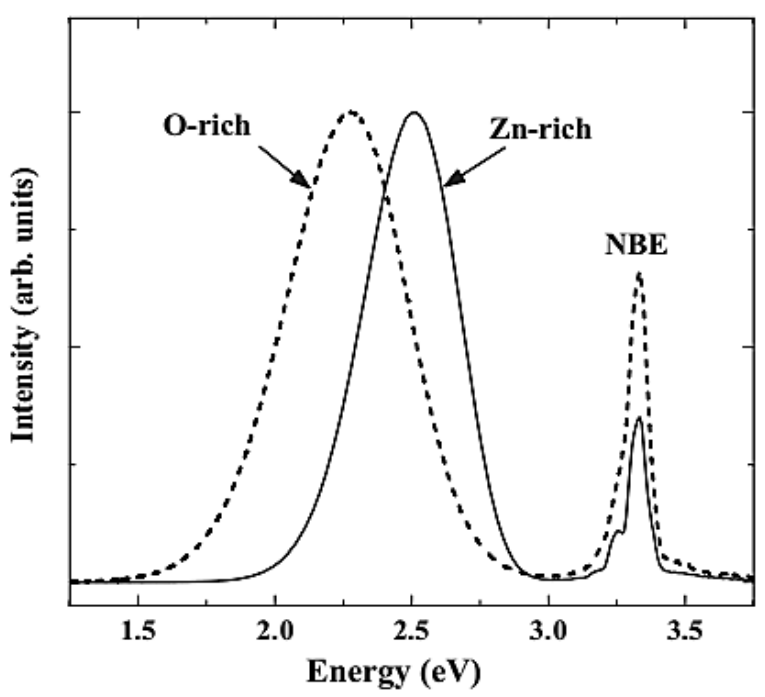

Figure 2. Cathodoluminescence spectra of $\mathrm{Zn}$ - and O-rich $\mathrm{ZnO}$ particles at $80 \mathrm{~K}$ (beam energy $=15 \mathrm{keV}$, beam current $=0.25 \mathrm{nA}$ ) normalized to the green peak height. Both $\mathrm{Zn}$ - and O-rich $\mathrm{ZnO}$ exhibit near-band-edge emission at $3.35 \mathrm{eV}$ but different green emission peak energies of 2.52 and $2.30 \mathrm{eV}$, respectively. Reprinted with permission from [18].

valence band maximum, respectively [11, 12], whereas these levels were calculated to be at 0.9 and $1.5 \mathrm{eV}$, respectively, by generalized gradient approximation (GGA) calculations [22]. When the Fermi level lies above the $1-/ 2-$ level, the equilibrium charge state is a negatively charged double acceptor $V_{\mathrm{Zn}}^{2-}$, which is formed by accepting two electrons from the valence band. Electron paramagnetic resonance (EPR) experiments have shown that the 1-/2- level of $V_{\mathrm{Zn}}$ lies at $\sim 1.0 \mathrm{eV}$ above the valence band maximum $[23,24]$. The slight variation in these data can be attributed to different calculation methods, or in the case of experiment, to diverse sample types, fabrication techniques, and growth conditions.

$\mathrm{Zn}$ vacancies are also considered to be responsible for the green emission band in $\mathrm{ZnO}[17,18]$. Sekiguchi et al. provided a strong argument in favor of $\mathrm{Zn}$ vacancies being the origin of green emission $[33,34]$. The authors reported that the hydrogen plasma treatment strongly passivates the green emission band in $\mathrm{ZnO}$ as $\mathrm{Zn}$ vacancies 
can readily interact with and be passivated by hydrogen. The peak positions of the reported $V_{\mathrm{Zn}}$-related green luminescence are found in the $2.2-2.5 \mathrm{eV}$ energy range (Table 2). Different research groups suggested different types of electronic transitions involving $V_{\mathrm{Zn}}$ defects to describe the green emission band, such as a shallow donor to a deep $V_{\mathrm{Zn}}$ acceptor [35], from the conduction band to $V_{\mathrm{Zn}}$ acceptor [27], from a $\mathrm{Zn}_{\mathrm{i}}$ donor to $V_{\mathrm{Zn}}$ acceptor level [36], and a hole transfer from divalent zinc vacancy $\left(V_{\mathrm{Zn}}^{2-}\right)$ and a monovalent $\left(V_{\mathrm{Zn}}^{-}\right)$defect [37]. The defect center responsible for the green luminescence in $\mathrm{ZnO}$ remains controversial.

\subsubsection{Zinc interstitials}

In the $\mathrm{ZnO}$ wurtzite lattice, $\mathrm{Zn}$ interstitials $\left(\mathrm{Zn}_{i}\right)$ act as donors and can occupy either octahedral or tetrahedral sites. However, $\mathrm{Zn}_{i}$ is more stable at the octahedral site because the tetrahedral site exhibits a higher formation energy [48]. Among the three charge states of zinc interstitials $\left(\mathrm{Zn}_{i}^{\circ}, \mathrm{Zn}_{i}^{+}\right.$, and $\left.\mathrm{Zn}_{i}^{2+}\right)$, the most stable state is $\mathrm{Zn}_{i}^{2+}$, which is formed by donating two electrons to the conduction band. Under equilibrium conditions, $\mathrm{Zn}_{i}$ has a high formation energy in n-type $\mathrm{ZnO}$ (as shown in Fig. 1) and is likely to be present in a negligible concentration [48]. Accordingly, $\mathrm{Zn}_{i}$ defects cannot be the source of the background n-type conductivity in $\mathrm{ZnO}$ even under Zn-rich conditions [48]. Additionally, there is general consensus that $\mathrm{Zn}_{i}$ are unstable at room temperature due to their high mobility. Nevertheless, it has been suggested that $\mathrm{Zn}_{i}$ defects can be a source of n-type conductivity under non-equilibrium conditions or by forming complexes involving $\mathrm{N}$ impurities [10]. For example, Hutson et al. reported the presence of $\mathrm{Zn}_{i}$ shallow donors with an activation energy of $51 \mathrm{meV}$ in Hall experiments [38] and Look et al. observed the presence of $\mathrm{Zn}_{i}$ shallow donors when $\mathrm{ZnO}$ samples were irradiated by a high-energy electron beam [39]. The formation energy of $\mathrm{Zn}_{i}$ falls with decreasing Fermi energy, indicating that they act as a compensating defect in p-type $\mathrm{ZnO}$ [48].

$\mathrm{Zn}_{i}$ is not considered to be an optically active luminescence center under equilibrium conditions, but this defect has been reported to be a source of blue and violet emissions in $\mathrm{ZnO}$ that was produced in 
highly non-equilibrium processes such as laser ablation and Zn-rich annealing [40, 41]. Halliburton et al. attributed an increased concentration of free carriers in the $\mathrm{ZnO}$ crystal annealed in $\mathrm{Zn}$ vapor [42] to $\mathrm{Zn}_{i}$ and proposed that the non-equilibrium conditions promote the formation of this defect. The peak positions of the reported $\mathrm{Zn}_{i^{-}}$ related blue/violet luminescence are found in the $2.54-2.85 \mathrm{eV}$ energy range as summarized in Table 2. Zeng et al. assigned the violet and blue emissions to the transitions from $\mathrm{Zn}_{i}$ and extended $\mathrm{Zn}_{i}$ states to the valance band, respectively [40].

\subsubsection{Oxygen interstitials}

Oxygen interstitials $\left(\mathrm{O}_{i}\right)$ can occupy either the octahedral interstitial site or tetrahedral interstitial site and are deep acceptors. First-principles calculations suggest that the tetrahedral interstitials are unstable, transforming into a split-interstitial configuration, also known as dumbbell configuration [14]. Conversely, $\mathrm{O}_{i}$ in the octahedral interstitial site are more stable and electrically active [49]. The octahedral $\mathrm{O}_{i}$ introduce $-/ 2-$ and $0 /-$ acceptor charge transition levels at 1.59 and $0.72 \mathrm{eV}$ above the valence band maximum, respectively [6]. The octahedral $\mathrm{O}_{i}$ configuration has high formation energy and its concentration is negligible in $\mathrm{ZnO}$ under equilibrium conditions. Janotti et al. reported that oxygen interstitials are electrically inactive in $p$-type $\mathrm{ZnO}$ and act as a deep acceptor when the Fermi level is greater than $2.8 \mathrm{eV}[6]$.

A broad yellow emission peaking in the energy range of $2.0-2.1 \mathrm{eV}$ has been reported in $\mathrm{ZnO}$ (Table 2) [43, 44]. This yellow emission band in $\mathrm{ZnO}$ has been attributed to $\mathrm{O}_{i}$ defects $[43,44]$. Moreover, several groups reported that the red emission centered at $\sim 1.80 \mathrm{eV}$ in $\mathrm{ZnO}$ nanostructures is related to $\mathrm{O}_{i}$ defects $[35,45]$. Figure 3 shows the deep level emission of the $\mathrm{ZnO}$ film that was annealed in $\mathrm{Ar}$ gas at $700^{\circ} \mathrm{C}$ and $900^{\circ} \mathrm{C}$ and subsequently treated by remote hydrogen plasma. The annealed $\mathrm{ZnO}$ films exhibit green (at $2.35 \mathrm{eV}$ ) and yellow (at $2.0 \mathrm{eV}$ ) emissions, which are both completely passivated by a hydrogen plasma, where the yellow emission is attributed to $\mathrm{O}_{i}$ defects [46]. The hydrogen plasma passivation of the $\mathrm{O}_{i}$-related yellow emission band in $\mathrm{ZnO}$ is consistent with its assignment to $\mathrm{O}_{i}$. 


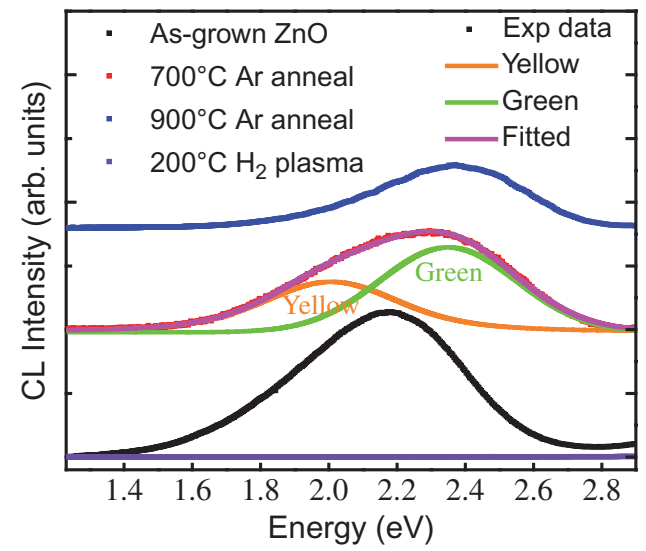

Figure 3. Cathodoluminescence spectra of the as-grown, $700^{\circ} \mathrm{C}$ and $900^{\circ} \mathrm{C}$ annealed undoped $\mathrm{ZnO}$ films (beam energy $=5 \mathrm{keV}$, beam current $=3 \mathrm{nA}$ ). The modeled CL spectra fitted with the yellow and green luminescence components. The emission spectrum from the film after being treated with remote hydrogen plasma (bottom spectrum) is also included and shows that the plasma treatment completely passivates both the green and yellow emission bands.

\section{3. Impurities and Defect Complexes}

5 The control of impurities and their associated charge states is of

In contrast, a similar yellow emission attributed to Li impurities in $\mathrm{ZnO}$ is not passivated by an equivalent hydrogen plasma treatment [46]. paramount importance in applications that exploit the wide range of properties of doped $\mathrm{ZnO}$. Intense research efforts have been focused on the fabrication and characterization of acceptor-doped $\mathrm{ZnO}$; however, reports of p-type samples are highly controversial. Incorporation of dopants into $\mathrm{ZnO}$ can also change the growth direction of $1 \mathrm{D}$ nanostructures; for example, $\mathrm{ZnO}$ nanorings and nanobelts can be produced using In as the dopant element [53, 54].

\subsection{Group I elements and hydrogen}

Group I ( $\mathrm{Li}, \mathrm{Na}$, and $\mathrm{K}$ ) elements are useful potential dopants for p-type $\mathrm{ZnO}$ and have been theoretically predicted to be shallow acceptors when substituting $\mathrm{Zn}$ atoms, whereas H (also a group I 
element) is a shallow donor. First-principles calculations and experiments have drawn attention to the role of hydrogen on the electronic and optical properties $\mathrm{ZnO}[55,56]$. It has been reported that that interstitial hydrogen acts as a shallow donor and its positive charge state $\left(\mathrm{H}_{i}^{+}\right)$is thermodynamically stable [6]. Hydrogen is a common impurity that can be unintentionally incorporated during growth of the most used techniques and can contribute to background n-type conductivity. First-principles calculations showed that hydrogen passivates $V_{\mathrm{Zn}}$ by the formation of a thermodynamically stable $\left(V_{\mathrm{Zn}}-H_{2}\right)$ neutral complex [34]. These defect complexes are electrically inactive [34]. This result is consistent with the experimental study that $H$ plasma treatment completely passivates the $V_{\mathrm{Zn}}$-related green emission band [18]. More recent theoretical work based on density function calculations suggests that hydrogen can form a $H-V_{\mathrm{O}}$ defect complex with the $\mathrm{O}$ vacancy, which has a low formation energy of about $1.7 \mathrm{eV}$ lower than that of $H_{i}$ [55]. Unlike $H_{i}$, this shallow donor complex is considered to be immobile at elevated temperatures and is responsible for the stability of high conductivity in $H$-doped $\mathrm{ZnO}$ films up to $250^{\circ} \mathrm{C}[55]$.

Group I impurities ( $\mathrm{Li}, \mathrm{Na}$, and $\mathrm{K}$ ) at the interstitial sites are donors but act as acceptors at the $\mathrm{Zn}$ substitutional site. Firstprinciples calculations have shown that $\mathrm{Li}, \mathrm{Na}$, and $\mathrm{K}$ elements are found to be deep acceptors located at $0.74,0.85$, and $1.26 \mathrm{meV}$ above the valence band maximum $[32,57]$. Based on the optical measurements, Meyer et al. and Kushnirenko et al. reported that $\mathrm{Li}_{\mathrm{Zn}}, \mathrm{Na}$, and $\mathrm{K}_{\mathrm{Zn}}$ are optically active acceptor centers, which give rise to shallow donor to deep acceptor recombination in the visible spectrum [58, 59]. Meyer et al. also reported that $\mathrm{Li}$ and $\mathrm{Na}$, incorporated either during growth or by diffusion, can introduce acceptors with a hole-binding energy of around $0.3 \mathrm{eV}$, which shows a donor-acceptor pair recombination [58]. Park et al. calculated the ionization energy of $0.09,0.17$, and $0.32 \mathrm{eV}$ for substitutional $\mathrm{Li}, \mathrm{Na}$, and $\mathrm{K}$, respectively [60].

A Li-related pair complex $\left(\mathrm{Li}_{\mathrm{Zn}}+\mathrm{Li}_{i}\right)$ can also be formed in $\mathrm{ZnO}$ under O-rich conditions [61]. Figures 4(a), 4(b) shows the local 
(a)

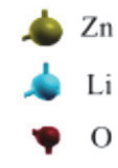

(b)
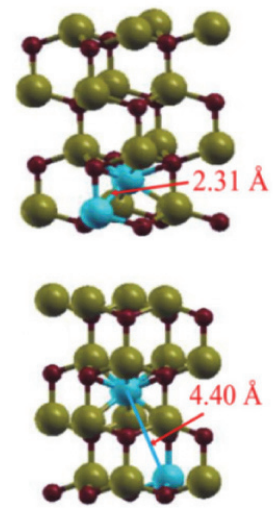

(c)

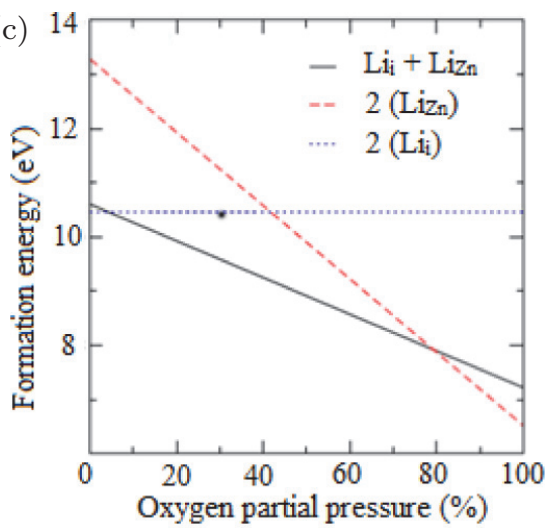

Figure 4. The local atomic geometry of $\mathrm{Li}_{\mathrm{Zn}}+\mathrm{Li}_{i}$ pair complexes for (a) nearest and (b) well-separated Li species (Reprinted with permission from [62]). (c) Formation energy of the $\mathrm{Lizn}_{\mathrm{Zn}}+\mathrm{Li}_{i}$ pair complex as a function of oxygen partial pressure. (Reprinted with permission from [57]).

atomic geometry of the $\mathrm{Li}_{\mathrm{Zn}}+\mathrm{Li}_{i}$ complex [62]. For both the O-rich and $\mathrm{Zn}$-rich conditions, the formation energy decreases for $\mathrm{Li}_{\mathrm{Zn}}$ and increases for $\mathrm{Li}_{i}$ with are increase in the Fermi level. Under O-rich conditions, the $\mathrm{Li}_{\mathrm{Zn}}+\mathrm{Li}_{i}$ pair complex has lower formation energy than either isolated $\mathrm{Li}_{\mathrm{Zn}}$ or $\mathrm{Li}_{i}$ defect (Fig. 4) [57]. Based on the firstprinciples calculations and photoluminescence measurements, Sahu et al. proposed that this acceptor-like complex is optically active and exhibits a visible emission band at $3.0 \mathrm{eV}$. EPR experiments showed that $\mathrm{Li}$ has two acceptor states at 0.85 and $0.15 \mathrm{eV}$ above the valence band maximum [63].

Group IB elements $(\mathrm{Cu}, \mathrm{Au}$, and $\mathrm{Ag})$ act as acceptors when incorporated at Zn sites. Under O-rich conditions, the formation energies of these acceptors are very low, but are considerably higher when located at interstitial sites [64]. The charge transition energies $(0 /-)$ for $\mathrm{Cu}_{\mathrm{Zn}}, \mathrm{Ag}_{\mathrm{Zn}}$, and $\mathrm{AuZn}$ are relatively high at 0.7 , 0.4 , and $0.5 \mathrm{eV}$ above the valence band maximum, respectively [64]. Group IB elements are better p-type dopants than IA elements due to their high ionization energy and less self-compensation by native donor defects. $\mathrm{Cu}$ favorably occupies the $\mathrm{Zn}$ site, $\left(\mathrm{Cu}_{\mathrm{Zn}}\right)$, which acts as an acceptor leading to the p-type conductivity and ferromagnetism 
$[65,66] . \mathrm{Cu}$ is a commonly incorporated impurity up to the ppm level in II-VI semiconductors; a large amount of work on Cu-doped $\mathrm{ZnO}$ exists concerning various aspects of $\mathrm{Cu}$ acceptor states and their possible role in structured green luminescence in $\mathrm{ZnO}$ crystals and nanostructures [67, 68]. Huang et al. [69] reported that $\mathrm{Cu}$ has three charge states, i.e. $\mathrm{Cu}_{\mathrm{Zn}}^{+}$or $\mathrm{Cu}^{3+}\left(3 \mathrm{~d}^{8} 4 \mathrm{~s}^{0}\right), \mathrm{Cu}_{\mathrm{Zn}}^{0}$ or $\mathrm{Cu}^{2+}\left(3 \mathrm{~d}^{9} 4 \mathrm{~s}^{0}\right)$, and $\mathrm{Cu}_{\mathrm{Zn}}^{-}$or $\mathrm{Cu}^{1+}\left(3 \mathrm{~d}^{10} 4 \mathrm{~s}^{0}\right)$. These defects have higher formation energies than native defects of $\mathrm{ZnO}$ in $\mathrm{Zn}$-rich conditions and have lower formation energies in O-rich conditions [69]. When the Fermi level is above the $\mathrm{Cu}^{2+} / \mathrm{Cu}^{1+}(0 /-)$ charge transition level, the equilibrium state is $\mathrm{Cu}^{1+}$, which is a negatively charged acceptor. With increasing $\mathrm{Cu}$ doping concentration in $\mathrm{ZnO}$, the $\mathrm{Cu}^{1+}$ state causes the $p$-type conductivity and the Fermi level shifts toward the valence band until the $\mathrm{Cu}^{2+} / \mathrm{Cu}^{1+}$ level is reached. First-principles calculations showed that the $\mathrm{Cu}$-doped $\mathrm{ZnO}$ is ferromagnetic when $\mathrm{Cu}$ atoms are present in $\mathrm{ZnO}$ in their $\mathrm{Cu}^{3+}$ and $\mathrm{Cu}^{2+}$ charge states, which exist only in p-type $\mathrm{ZnO}$ [69]. Conversely, $\mathrm{Cu}$-doped $\mathrm{ZnO}$ was found to be nonmagnetic when $\mathrm{Cu}$ atoms stay in the $\mathrm{Cu}^{1+}$ state. The charge states of $\mathrm{Cu}$ can be also mediated by doping $\mathrm{ZnO}$ with $\mathrm{Ga}$, which pushes the Fermi level above the $\mathrm{Cu}^{2+} / \mathrm{Cu}^{1+}$ transition level [68]. The position of this $\mathrm{Cu}^{2+} / \mathrm{Cu}^{1+}$ level is still a matter of great controversy: Wardle et al. [70] estimated this transition level to be at $1.0 \mathrm{eV}$ above the valence band maximum, while Yan et al. [64] gave a value of $0.7 \mathrm{eV}$. Electrical measurements on $\mathrm{Cu}$-doped $\mathrm{ZnO}$ revealed that the $0 /-$ level lies at $0.2 \mathrm{eV}$ below the conduction band minimum [71]. Admittance spectroscopy and photoluminescence experiments have shown that $\mathrm{Cu}$ has two acceptor levels at $\mathrm{E}_{\mathrm{c}}-0.17$ and $\mathrm{E}_{\mathrm{v}}+0.4 \mathrm{eV}$ $[72,73]$.

\subsection{Group-II element ( $M g$ )}

$\mathrm{Mg}$ energetically prefers to occupy the $\mathrm{Zn}$ site and induces substitutional defects acting as acceptors in $\mathrm{ZnO}$ [74]. Alloying $\mathrm{ZnO}$ films with $\mathrm{MgO}$ is a commonly used method for tuning the bandgap of $\mathrm{ZnO}$ [75]. $\mathrm{Mg}$ can also occupy either octahedral interstitial site 
$\left(\mathrm{Mg}_{i}^{\mathrm{O}}\right)$ or tetrahedral interstitial site $\left(\mathrm{Mg}_{i}^{\mathrm{T}}\right)$. The formation energy of $\mathrm{Mg}_{i}$ is higher than that of $\mathrm{Mg}_{\mathrm{Zn}}$ for all Fermi energies except under Zn-rich conditions where the formation energy of $\mathrm{Mg}_{i}$ is lower when the Fermi level is near the valence band maximum (see Fig. 5) [74]. Since the Fermi level is always close to the conduction band in $\mathrm{ZnO}$ due to its inherent n-type conductivity, $\mathrm{Mg}_{\mathrm{Zn}}$ is the most thermodynamically stable defect type under both O- and Zn-rich conditions. The substitutional $\mathrm{Mg}_{\mathrm{Zn}}$ in $\mathrm{ZnO}$ lowers the formation energy of $\mathrm{Zn}$ vacancies $\left(V_{\mathrm{Zn}}\right)$ by $\sim 2.1 \mathrm{eV}$ and thereby promotes the formation of $V_{Z n}$ centers [76]. This prediction is consistent with the photoluminescence results, revealing that doping $\mathrm{ZnO}$ with $\mathrm{Mg}$ significantly enhances the $V_{\mathrm{Zn}}$-related green luminescence band [77]. First-principles calculations showed that $\mathrm{Mg}_{\mathrm{Zn}}$ can interact with the donor-like defects $\left(V_{\mathrm{O}}\right.$ and $\left.\mathrm{Zn}_{i}\right)$ of $\mathrm{ZnO}$, forming the $\mathrm{Mg}_{\mathrm{Zn}}-\mathrm{Zn}_{i}$ and $\mathrm{Mg}_{\mathrm{Zn}}-V_{\mathrm{O}}$ defect complexes [76]. This is in agreement with the experimental result that $\mathrm{Mg}$ doping quenches the $V_{\mathrm{O}}$-related visible emission band in $\mathrm{ZnO}$ [78].

\subsection{Group III elements}

The group III elements ( $\mathrm{Ga}, \mathrm{Al}$, and $\mathrm{In})$ are well-known n-type dopants in $\mathrm{ZnO}$. $\mathrm{Al}$ and $\mathrm{Ga}$ are favored donors for transparent conductor applications; high doping levels of $n \sim 10^{20} \mathrm{~cm}^{-3}$ can make $\mathrm{ZnO}$ electrically conductive and optically transparent [79]. Group III elements are preferably incorporated at $\mathrm{Zn}$ sites and induce substitutional defects in $\mathrm{ZnO}$ [80]. They can also be accommodated at either the octahedral interstitial site $\left(\mathrm{Ga}_{i}^{\mathrm{O}}\right)$ or the tetrahedral interstitial site $\left(\mathrm{Ga}_{i}^{\mathrm{T}}\right)$. The formation energies of these dopants at interstitial sites are much higher than those on substitutional sites and their concentrations are negligible when grown under equilibrium conditions [80, 81]. Theoretical and experimental studies showed that the group III elements can interact with native acceptor-like defects $\left(V_{\mathrm{Zn}}\right.$ and $\mathrm{O}_{i}$ ), generating high concentrations of $\mathrm{Ga}_{\mathrm{Zn}}-V_{\mathrm{Zn}}$ and $\mathrm{Ga}_{\mathrm{Zn}}-\mathrm{O}_{i}$ defect complexes due to the Coulomb interaction between donor and acceptor centers $[82,83]$. The local atomic geometry of $\mathrm{Ga}_{\mathrm{Zn}}-V_{\mathrm{Zn}}$ 


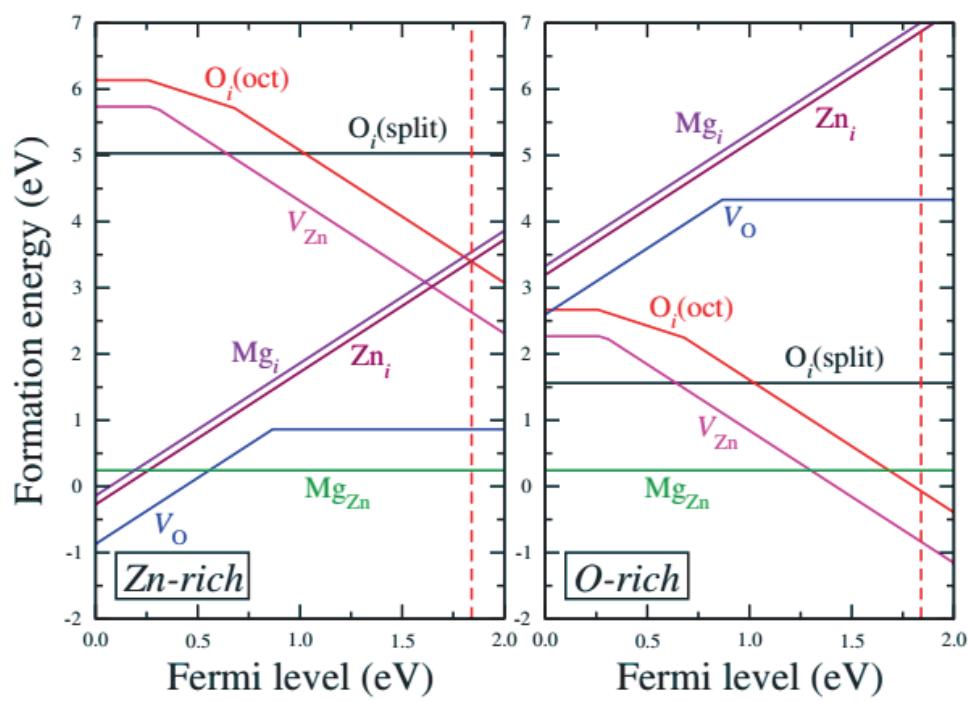

Figure 5. The formation energies of $\mathrm{Mg}$ defects in comparison with native defects in $\mathrm{ZnO}$ under $\mathrm{Zn}$-rich and O-rich conditions. The Fermi level is referenced to the valence band maximum. Reprinted with permission from [74].

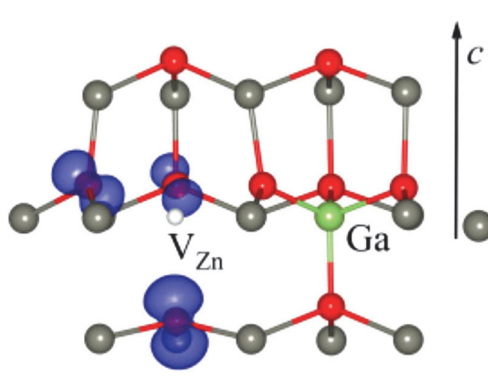

(a)

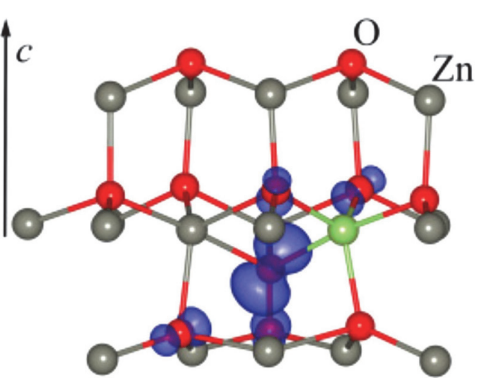

(b)

Figure 6. Local atomic geometry for (a) $\mathrm{GaZn}_{\mathrm{Zn}}-V_{\mathrm{Zn}}$ and (b) $\mathrm{GaZn}_{\mathrm{Zn}}-\mathrm{O}_{i}$ complexes in Ga-doped $\mathrm{ZnO}$. Both defect complexes act as deep acceptors and are electrically active in $\mathrm{ZnO}$. Reprinted with permission from [82].

and $\mathrm{Gazn}_{\mathrm{Zn}}-\mathrm{O}_{i}$ defect complexes are shown in Fig. 6. These defects act as acceptors and are electrically active in $\mathrm{ZnO}$.

Under O-rich conditions, the $\mathrm{GaZn}-V_{\mathrm{Zn}}$ acceptor complex has 4 significantly lower formation energy than the isolated substitutional 
Gazn donors when the Fermi energy is close to the conduction band minimum (Fig. 6) and is responsible for appreciable defect compensation in highly Ga-doped $\mathrm{ZnO}$. These theoretical predictions were verified by experimental results, which reported that both the electrical conductivity and carrier concentration significantly decrease at high Ga doping concentrations when samples were grown under O-rich conditions $[84,85]$. The formation energy of Gazn $-\mathrm{O}_{\mathrm{i}}$ is higher than GaZn $-V_{\mathrm{Zn}}$, indicating that the compensation effect due to the $\mathrm{GaZn}_{\mathrm{Z}}-\mathrm{O}_{\mathrm{i}}$ complex in Ga-doped $\mathrm{ZnO}$ is weaker. In Opoor conditions, the formation energies of these defect complexes are substantially higher (Fig. 7), suggesting that the compensation mechanism is less pronounced. Several experimental and theoretical studies showed that the $\mathrm{GaZn}_{\mathrm{Zn}}-V_{\mathrm{Zn}}$ and $\mathrm{GaZn}_{\mathrm{Zn}}-\mathrm{O}_{\mathrm{i}}$ complexes have ionization energies of about 0.75 and $0.66 \mathrm{eV}$ above the valence band maximum, respectively $[82,86]$.

\subsection{Group IV elements}

Theoretical investigations showed that group IV elements $(\mathrm{C}, \mathrm{Si}$, and $\mathrm{Sn}$ ) act as donors when occupying the $\mathrm{Zn}$ site in $\mathrm{ZnO}$ and that $\mathrm{ZnO}$ can be made highly conductive and transparent in the visible region by doping with Si [87]. However, there has been little evidence that these elements are incorporated at an appreciable level into $\mathrm{ZnO}$ crystals. Carbon is a common impurity in chemical vapor transport growth with graphite and MOCVD; it was theoretically predicted that $\mathrm{C}$ could either occupy in the substitutional Znor O-sites, forming $\mathrm{C}_{\mathrm{Zn}}$ donor or $\mathrm{C}_{\mathrm{O}}$ acceptor [88]. Based on firstprinciples calculations, $\mathrm{Lu}$ et al. [89] predicted that $\mathrm{C}_{\mathrm{O}}$ interacts with the donor-like defects $\left(V_{\mathrm{O}}\right.$ and $\left.\mathrm{Zn}_{i}\right)$, forming $\mathrm{C}_{\mathrm{O}}-V_{\mathrm{O}}, \mathrm{C}_{\mathrm{O}}-\mathrm{Zn}_{\mathrm{i}}$, and $2 \mathrm{C}_{\mathrm{O}}-V_{\mathrm{O}}-\mathrm{Zn}_{i}$ defect complexes. The authors claimed that the $\mathrm{C}_{\mathrm{O}}-\mathrm{Zn}_{\mathrm{i}}$ and $2 \mathrm{C}_{\mathrm{O}}-V_{\mathrm{O}}-\mathrm{Zn}_{i}$ complexes have a low formation energy as shown in Fig. 8 and are the possible source of green and red emissions in $\mathrm{ZnO}$, respectively. This prediction is consistent with photoluminescence studies of C-doped $\mathrm{ZnO}$ [90]. Combination of density function calculations and optical measurements showed that $\mathrm{Sn}$ doping of $\mathrm{ZnO}$ quantum dots eliminates $V_{\mathrm{O}}$ while creating $\mathrm{O}_{\mathrm{Zn}}$ and 


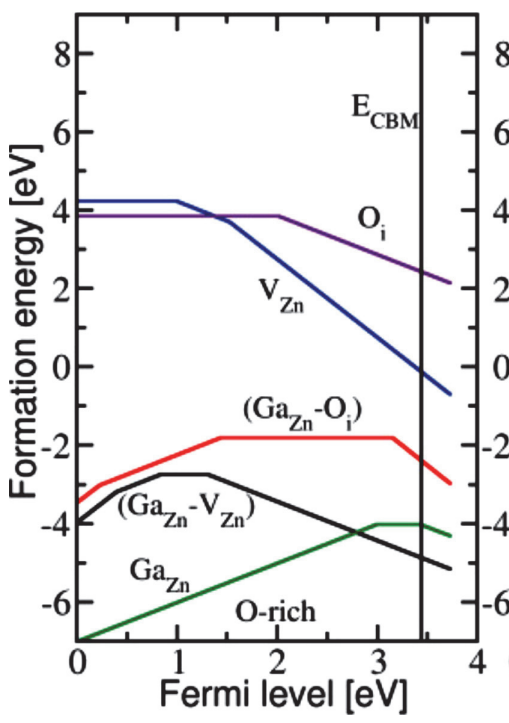

(a)

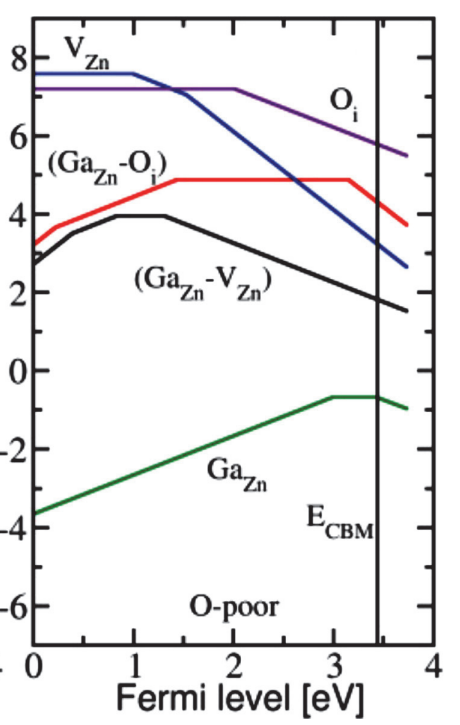

(b)

Figure 7. Formation energies of Ga-related defects as a function of Fermi level in (a) O-rich and (b) O-poor conditions. The zero value of the Fermi level corresponds to the valence band maximum and the "kinks" in the curves indicate transitions between the defect charge states. Under the O-rich condition, both $\mathrm{Gazn}_{\mathrm{Z}}-V_{\mathrm{Zn}}$ and $\mathrm{GaZn}_{\mathrm{z}}-\mathrm{O}_{\mathrm{i}}$ complexes can efficiently form due to their low formation energies and play an important role as compensating defects in Ga-doped $\mathrm{ZnO}$. Reprinted with permission from [82].

$\mathrm{O}_{i}$ defects as a result of conversion from $\mathrm{Sn}^{4+}$ to $\mathrm{Sn}^{2+}$ state with increasing Sn doping concentration [91].

\section{3.5. Group V elements}

${ }_{4}$ The greatest challenge in research on $\mathrm{ZnO}$ is the achievement of 5 reliable and reproducible p-type doping. Group V (N, P, As, and $6 \mathrm{Sb}$ ) elements are the most promising candidates for p-type doping, 7 but unfortunately, most of these dopants form deep acceptors. The 8 substitutional $X_{\mathrm{O}}($ where $\mathrm{X}=\mathrm{N}, \mathrm{P}, \mathrm{As}$, and $\mathrm{Sb}$ ) at the $\mathrm{O}$ site is a deep 9 acceptor and is unlikely to contribute for the p-type conduction in 10 $\mathrm{ZnO}$, while the substitutional $X_{\mathrm{Zn}}$ at the $\mathrm{Zn}$ site exhibits donor-like 11 behavior [7, 92]. First-principles calculations show that $\mathrm{N}$ substitut${ }_{12}$ ing an $\mathrm{O}$ is a deep acceptor with a hole binding energy of $0.4 \mathrm{eV}$ [60], 


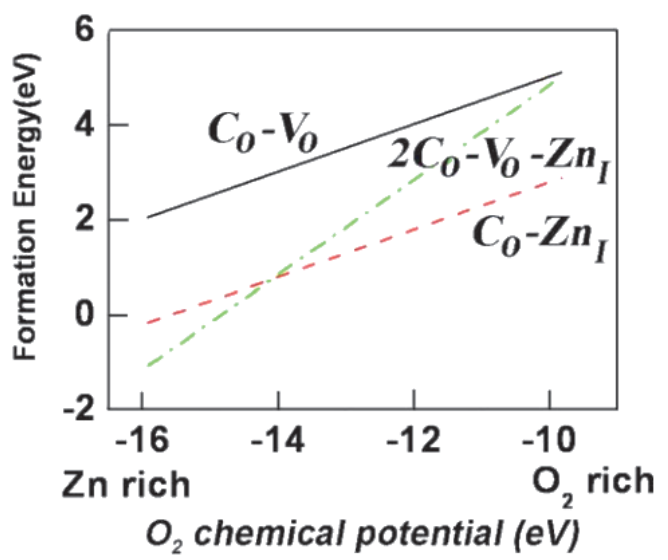

Figure 8. Calculated formation energies of carbon defect complexes as a function of $\mathrm{O}_{2}$ chemical potential. The complexes are $\mathrm{C}_{\mathrm{O}}-V_{\mathrm{O}}$ (black line), $\mathrm{C}_{\mathrm{O}}-\mathrm{Zn}_{i}$ (red) and $2 \mathrm{C}_{\mathrm{O}}-V_{\mathrm{O}}-\mathrm{Zn}_{i}$ (green). Reprinted with permission from [89].

while photoluminescence experiments revealed a hole binding energy of $\sim 0.2 \mathrm{eV}$ [93]. X-ray electron and X-ray absorption spectroscopies on $\mathrm{N}$-doped $\mathrm{ZnO}$ showed that $\mathrm{N}$ exists in three chemical states, attributed to $\mathrm{N}_{\mathrm{O}}, \mathrm{N}_{\mathrm{Zn}}$, and $\mathrm{N}_{2}$ molecules, and a direct correlation was observed between the N-related donor-acceptor pair emission and the concentration of $\mathrm{N}_{2}[94,95]$. The experimental observations are in agreement with first-principles calculations which predict that $\mathrm{N}_{2}$ at the $\mathrm{Zn}$ site is a shallow acceptor [96].

$\mathrm{P}, \mathrm{As}$, and $\mathrm{Sb}$ have significantly larger ionic radii than $\mathrm{O}$, and according to the first-principles calculations, they act as deep acceptors when accommodated at the $O$ substitutional site [60]. Nevertheless, p-type conductivity in $\mathrm{P}$-doped $\mathrm{ZnO}$ has been reported by several groups [97, 98]. Modeling also predicted that the substitutional $X_{Z n}$ interacts with $\mathrm{Zn}$ vacancies, forming an acceptor complex $\mathrm{X}_{\mathrm{Zn}}-2 V_{\mathrm{Zn}}[92,99]$. The formation energies of P-induced defects and complexes in $\mathrm{ZnO}$ are displayed in Fig. 8. Under O-rich conditions, the $\mathrm{P}_{\mathrm{Zn}}-2 V_{\mathrm{Zn}}$ acceptor complex has a lower formation energy than the other defects, the calculated transition level $(+/-)$ for this complex is $150 \mathrm{meV}$ above the valence band maximum [99]. This calculated value seems to be in qualitative agreement with the experimental investigations that report an acceptor level in the range 


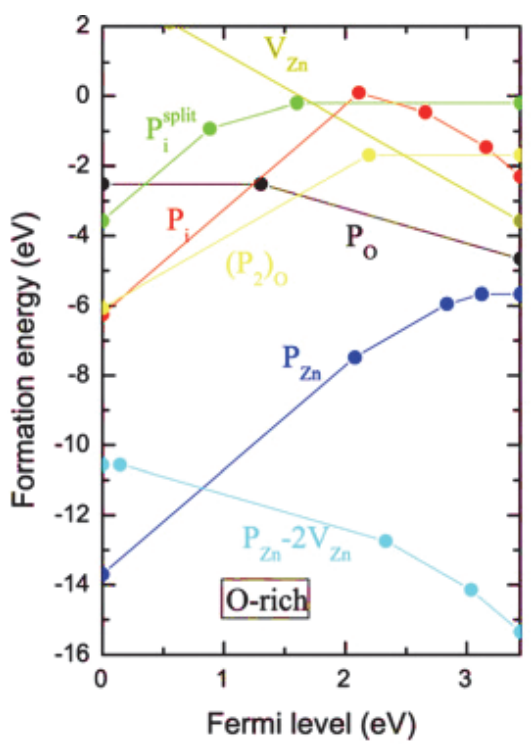

(a)

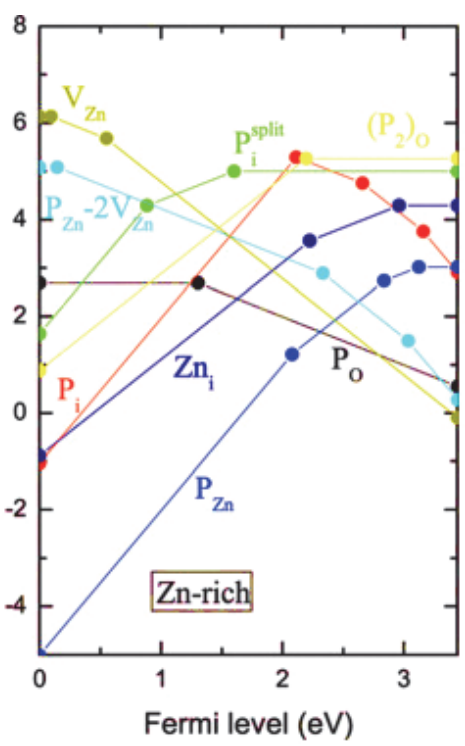

(b)

Figure 9. Formation energy of native and $\mathrm{P}$-induced defects in $\mathrm{ZnO}$ under O-rich and Zn-rich conditions. Reprinted with permission from [99].

of 120 - $180 \mathrm{meV}$ for P-doped $\mathrm{ZnO}[98,100]$. Photoluminescence 2 and Hall measurements of Sb-doped $\mathrm{ZnO}$ films also showed that 3 the incorporation of $\mathrm{Sb}$ induces the formation of $\mathrm{Sb}_{\mathrm{Zn}}-2 V_{\mathrm{Zn}}$ shal4 low acceptor complex with a binding energy $161 \mathrm{meV}$, responsible 5 for their p-type conduction [101]. Further experiments and modeling need to be performed to confirm the microscopic structure of these acceptor complexes.

\section{Conclusions}

Recent theoretical and experimental investigations have provided further insight into the nature of point defects, impurities, and dopants in $\mathrm{ZnO}$ and their effect on the electrical and optical properties. Significant progress has been made in recent years in fabricating of high-quality $\mathrm{ZnO}$ samples suitable for detailed and systematic investigations of defect characteristics. Yet, several significant questions concerning the fundamental properties of defects and their roles in the performance of $\mathrm{ZnO}$-based devices remain largely 
unresolved. The ultimate goal of being able to reproducibly fabricate, high-quality p-type $\mathrm{ZnO}$ has not been met. This review emphasizes that comprehensive studies aimed at understanding and controlling native and impurity-induced defects are essential for the development of practical $\mathrm{ZnO}$ devices with bespoke properties for specific applications. Elements in several periodic table groups have been considered as potential dopants in $\mathrm{ZnO}$. The electronic and optical properties of the host $\mathrm{ZnO}$ were found to be influenced in a similar way upon doping with elements from the same group. Group I elements act as deep acceptors when residing on a substitutional Zn site and are responsible for the yellow emission in $\mathrm{ZnO}$. Group I atoms at interstitial sites behave as shallow acceptors and have been reported to yield p-type conductivity in $\mathrm{ZnO}$, but the exact nature of these acceptors is not yet clear. $\mathrm{Mg}$ from group II has been proved effective in engineering the bandgap of ZnO. Group III elements, specifically Al, Ga, and $\mathrm{H}$, account for the n-type behavior of $\mathrm{ZnO}$ in most circumstances. $\mathrm{Al}$ and $\mathrm{Ga}$ are the preferred donors for transparent conductor applications, but these donors could be compensated via the formation of acceptor complexes with either $\mathrm{Zn}$ vacancies or $\mathrm{O}$ interstitials. Both of the acceptor complex types are known to be electrically and optically active. Little is known about the incorporation of $\mathrm{C}$ and $\mathrm{Si}$, but many studies claim that these group IV dopants can make $\mathrm{ZnO}$ films highly conductive for transparent electrical contacts. Group V dopants, in particular $\mathrm{N}$ and $\mathrm{P}$, are considered to be the natural choice for p-type doping; however, the origin of p-type response in $\mathrm{ZnO}$ doped with $\mathrm{N}$ or $\mathrm{P}$ remains controversial due to the formation of compensating defects and their low solubility. $\mathrm{ZnO}$ holds great promise for a range of photonic and optoelectronic applications, it is hoped that new fundamental insights from reliable characterization of defects will lead to transformative breakthroughs in practical $\mathrm{ZnO}$ devices.

\section{Acknowledgments}

Financial support from the Australian Research Council (ARC) under the Discovery Project funding scheme (project number DP150103317) is acknowledged. 


\section{References}

[1] X. Huang, Nat. Photon. 8, 748 (2014).

[2] M. A. Rahman, J. A. Scott, A. Gentle, M. R. Phillips, C. Ton-That, Nanotechnology 29, 425707 (2018).

[3] Y. Tang, Z. Chen, H. Song, C. Lee, H. Cong, H. Cheng, W. Zhang, I. Bello, S. Lee, Nano Lett. 8, 4191 (2008).

[4] S. Chu, G. Wang, W. Zhou, Y. Lin, L. Chernyak, J. Zhao, J. Kong, L. Li, J. Ren, J. Liu, Nat. Nanotechnol. 6, 506 (2011).

[5] S. N. Das, J. P. Kar, J.-H. Choi, T. I. Lee, K.-J. Moon, J.-M. Myoung, J. Phys. Chem. C 114, 1689 (2010).

[6] A. Janotti and C. G. Van de Walle, Rep. Prog. Phys. 72, 126501 (2009).

[7] Ü. Özgür, Y. I. Alivov, C. Liu, A. Teke, M. Reshchikov, S. Doğan, V. Avrutin, S.-J. Cho, H. Morkoc, J. Appl. Phys. 98, 11 (2005).

[8] A. B. Djurisic, A. M. C. Ng, X. Y. Chen, Prog. Quant. Electron. 34, 191 (2010).

[9] F. Selim, M. Weber, D. Solodovnikov, K. Lynn, Phys. Rev. Lett. 99, 085502 (2007).

[10] D. C. Look, G. C. Farlow, P. Reunchan, S. Limpijumnong, S. Zhang, K. Nordlund, Phys. Rev. Lett. 95, 225502 (2005).

[11] A. Kohan, G. Ceder, D. Morgan, C. G. Van de Walle, Phys. Rev. B 61, 15019 (2000).

[12] A. Janotti, C. G. Van de Walle, Phys. Rev. B 76, 165202 (2007).

[13] A. Janotti, C. G. Van de Walle, Appl. Phys. Lett. 87, 122102 (2005).

[14] P. Erhart, K. Albe, A. Klein, Phys. Rev. B 73, 205203 (2006).

[15] A. Janotti, C. G. Van de Walle, Nat. Mater. 6, 44 (2007).

[16] F. Leiter, H. Alves, A. Hofstaetter, D. Hofmann, B. Meyer, Phys. Status Solidi B 226, R4 (2001).

[17] T. M. Børseth, B. Svensson, A. Y. Kuznetsov, P. Klason, Q. Zhao, M. Willander, Appl. Phys. Lett. 89, 262112 (2006).

[18] C. Ton-That, L. Weston, M. Phillips, Phys. Rev. B 86, 115205 (2012).

[19] J. Ye, S. Gu, F. Qin, S. Zhu, S. Liu, X. Zhou, W. Liu, L. Hu, R. Zhang, Y. Shi, Appl. Phys. A 81, 759 (2005).

[20] D. Hofmann, D. Pfisterer, J. Sann, B. Meyer, R. Tena-Zaera, V. MunozSanjose, T. Frank, G. Pensl, Appl. Phys. A 88, 147 (2007).

[21] F. Tuomisto, V. Ranki, K. Saarinen, D. C. Look, Phys. Rev. Lett. 91, 205502 (2003).

[22] S. Lany, A. Zunger, Phys. Rev. Lett. 98, 045501 (2007).

[23] X. Wang, L. Vlasenko, S. Pearton, W. Chen, I. A. Buyanova, J. Phys. D: Appl. Phys. 42, 175411 (2009).

[24] S. Evans, N. Giles, L. Halliburton, L. Kappers, J. Appl. Phys. 103, 043710 (2008).

[25] S. Lima, F. Sigoli, M. Jafelicci Jr, M. R. Davolos, Int. J. Inorg. Mater. 3, 749 (2001). 
[26] V. Nikitenko, Zinc Oxide - A Material for Micro-and Optoelectronic Applications (Springer, 2005), p. 69.

[27] P. Thiyagarajan, M. Kottaisamy, N. Rama, M. R. Rao, Scripta Mater. 59, 722 (2008).

[28] A. Djurišić, A. Ng, X. Chen, Prog. Quant. Electron. 34, 191 (2010).

[29] B. Lin, Z. Fu, Y. Jia, Appl. Phys. Lett. 79, 943 (2001).

[30] S. Choi, M. R. Phillips, I. Aharonovich, S. Pornsuwan, B. C. Cowie, C. Ton-That, Adv. Opt. Mater. 3, 821 (2015).

[31] P. Xu, Y. Sun, C. Shi, F. Xu, H. Pan, Nucl. Instr. Meth. Phys. Res. B 199, 286 (2003).

[32] J. Hu, B. Pan, J. Chem. Phys. 129, 154706 (2008).

[33] C. G. Van de Walle, Phys. Rev. Lett. 85, 1012 (2000).

[34] E. Lavrov, J. Weber, F. Börrnert, C. G. Van de Walle, R. Helbig, Phys. Rev. B 66, 165205 (2002).

[35] N. Alvi, K. Ul Hasan, O. Nur, M. Willander, Nanoscale Res. Lett. 6, 130 (2011).

[36] A. Escobedo-Morales, U. Pal, Appl. Phys. Lett. 93, 193120 (2008).

[37] C. Xu, X. Sun, X. Zhang, L. Ke, S. Chua, Nanotechnol. 15, 856 (2004).

[38] D. Thomas, J. Phys. Chem. Solids 3, 229 (1957).

[39] D. C. Look, J. W. Hemsky, J. Sizelove, Phys. Rev. Lett. 82, 2552 (1999).

[40] H. Zeng, G. Duan, Y. Li, S. Yang, X. Xu, W. Cai, Adv. Funct. Mater. 20, $561(2010)$.

[41] C. H. Ahn, Y. Y. Kim, D. C. Kim, S. K. Mohanta, H. K. Cho, J. Appl. Phys. 105, 013502 (2009).

[42] L. Halliburton, N. Giles, N. Garces, M. Luo, C. Xu, L. Bai, L. A. Boatner, Appl. Phys. Lett. 87, 172108 (2005).

[43] X. Wu, G. Siu, C. Fu, H. Ong, Appl. Phys. Lett. 78, 2285 (2001).

[44] A. R. Gheisi, C. Neygandhi, A. K. Sternig, E. Carrasco, H. Marbach, D. Thomele, O. Diwald, Phys. Chem. Chem. Phys. 16, 23922 (2014).

[45] X. Liu, X. Wu, H. Cao, R. Chang, J. Appl. Phys. 95, 3141 (2004).

[46] Z. Wang, C. Luo, W. Anwand, A. Wagner, M. Butterling, M. A. Rahman, M. R. Phillips, C. Ton-That, M. Younas, S. Su, Sci. Rep. 9, 3534 (2019).

[47] J. Lv, C. Li, Appl. Phys. Lett. 103, 232114 (2013).

[48] D. Reynolds, D. C. Look, B. Jogai, J. Appl. Phys. 89, 6189 (2001).

[49] S. Anantachaisilp, S. M. Smith, C. Ton-That, S. Pornsuwan, A. R. Moon, C. Nenstiel, A. Hoffmann, M. R. Phillips, J. Lumin. 168, 20 (2015).

[50] S. Anantachaisilp, S. M. Smith, C. Ton-That, T. Osotchan, A. R. Moon, M. R. Phillips, J. Phys. Chem. C 118, 27150 (2014).

[51] V. Kumar, H. Swart, O. Ntwaeaborwa, R. Kroon, J. Terblans, S. Shaat, A. Yousif, M. Duvenhage, Mater. Lett. 101, 57 (2013).

[52] M. Patra, K. Manzoor, M. Manoth, S. Vadera, N. Kumar, J. Lumin. 128, 267 (2008).

[53] X. Y. Kong, Y. Ding, R. Yang, Z. L. Wang, Science 303, 1348 (2004).

[54] X. Y. Kong, Z. L. Wang, Nano Lett. 3, 1625 (2003). 
[55] W. Chen, L. Zhu, Y. Li, L. Hu, Y. Guo, H. Xu, Z. Ye, Phys. Chem. Chem. Phys. 15, 17763 (2013).

[56] R. C. Wang, C. F. Cheng, Plasma Process. Polym. 12, 51 (2015).

[57] R. Vidya, P. Ravindran, H. Fjellvåg, J. Appl. Phys. 111, 123713 (2012).

[58] B. K. Meyer, J. Stehr, A. Hofstaetter, N. Volbers, A. Zeuner, J. Sann, Appl. Phys. A 88, 119 (2007).

[59] V. Kushnirenko, I. Markevich, T. Zashivailo, J. Lumin. 132, 1953 (2012).

[60] C. Park, S. Zhang, S.-H. Wei, Phys. Rev. B 66, 073202 (2002).

[61] A. Carvalho, A. Alkauskas, A. Pasquarello, A. Tagantsev, N. Setter, Phys. Rev. B 80, 195205 (2009).

[62] R. Sahu, K. Dileep, B. Loukya, R. Datta, Appl. Phys. Lett. 104, 051908 (2014).

[63] C. Rauch, W. Gehlhoff, M. Wagner, E. Malguth, G. Callsen, R. Kirste, B. Salameh, A. Hoffmann, S. Polarz, Y. Aksu, J. Appl. Phys. 107, 024311 (2010).

[64] Y. Yan, M. Al-Jassim, S.-H. Wei, Appl. Phys. Lett. 89, 181912 (2006).

[65] D. Buchholz, R. Chang, J.-Y. Song, J. Ketterson, Appl. Phys. Lett. 87, 082504 (2005).

[66] C.-L. Hsu, Y.-D. Gao, Y.-S. Chen, T.-J. Hsueh, ACS Appl. Mater. Interfaces 6, 4277 (2014).

[67] N. Garces, L. Wang, L. Bai, N. Giles, L. Halliburton, G. Cantwell, Appl. Phys. Lett. 81, 622 (2002).

[68] M. A. Rahman, M. T. Westerhausen, C. Nenstiel, S. Choi, A. Hoffmann, A. Gentle, M. R. Phillips, C. Ton-That, Appl. Phys. Lett. 110, 121907 (2017).

[69] D. Huang, Y.-J. Zhao, D.-H. Chen, Y.-Z. Shao, Appl. Phys. Lett. 92, 182509 (2008).

[70] M. Wardle, J. Goss, P. Briddon, Phys. Rev. B 72, 155108 (2005).

[71] E. Mollwo, G. Müller, P. Wagner, Solid State Commun. 13, 1283 (1973).

[72] M. A. Reshchikov, V. Avrutin, N. Izyumskaya, R. Shimada, H. Morkoc, S. Novak, J. Vac. Sci. Technol. 27, 1749 (2009).

[73] Y. Kanai, Jpn. J. Appl. Phys. 30, 703 (1991).

[74] N. Palakawong, J. Jutimoosik, J. T-Thienprasert, S. Rujirawat, S. Limpijumnong, Integrated Ferroelectrics 156, 72 (2014).

[75] A. K. Sharma, J. Narayan, J. F. Muth, C. W. Teng, C. Jin, A. Kvit, R. M. Kolbas, O. W. Holland, Appl. Phys. Lett. 75, 3327 (1999).

[76] R. Dutta, N. Mandal, Appl. Phys. Lett. 101, 042106 (2012).

[77] E. B. Manaia, R. C. K. Kaminski, B. L. Caetano, V. Briois, L. A. Chiavacci, C. Bourgaux, Eur. J. Nanomed. 7, 109 (2015).

[78] J. Perkins, G. Foster, M. Myer, S. Mehra, J. Chauveau, A. Hierro, A. Redondo-Cubero, W. Windl, L. Brillson, APL Mater. 3, 062801 (2015).

[79] H. J. Ko, Y. F. Chen, S. K. Hong, H. Wenisch, T. Yao, D. C. Look, Appl. Phys. Lett. 77, 3761 (2000).

[80] R. Saniz, Y. Xu, M. Matsubara, M. Amini, H. Dixit, D. Lamoen, B. Partoens, J. Phys. Chem. Solids 74, 45 (2013). 
[81] Y.-S. Lee, Y.-C. Peng, J.-H. Lu, Y.-R. Zhu, H.-C. Wu, Thin Solid Films 570, 464 (2014).

[82] D. Demchenko, B. Earles, H. Liu, V. Avrutin, N. Izyumskaya, Ü. Özgür, H. Morkoç, Phys. Rev. B 84, 075201 (2011).

[83] M.-H. Lee, Y.-C. Peng, H.-C. Wu, J. Alloys Compd. 616, 122 (2014).

[84] T. Yamada, K. Ikeda, S. Kishimoto, H. Makino, T. Yamamoto, Surf. Coat. Technol. 201, 4004 (2006).

[85] C.-Y. Tsay, K.-S. Fan, C.-M. Lei, J. Alloys Compd. 512, 216 (2012).

[86] A. Tang, Z. Mei, Y. Hou, L. Liu, V. Venkatachalapathy, A. Azarov, A. Kuznetsov, X. Du, Sci. China Phys., Mech. E Astron. 61, 077311 (2018).

[87] J. Liu, X. Fan, C. Sun, W. Zhu, Chem. Phys. Lett. 649, 78 (2016).

[88] S. Panpan, S. Xiyu, H. Qinying, L. Yadong, C. Wei, J. Semicond. 30, 052001 (2009).

[89] Y. Lu, Z. Hong, Y. Feng, S. Russo, Appl. Phys. Lett. 96, 091914 (2010).

[90] L. Tseng, J. Yi, X. Zhang, G. Xing, H. Fan, T. Herng, X. Luo, M. Ionescu, J. Ding, S. Li, AIP Adv. 4, 067117 (2014).

[91] W. Yang, B. Zhang, Q. Zhang, L. Wang, B. Song, Y. Ding, C. Wong, RSC Adv. 7, 11345 (2017).

[92] G. Petretto, F. Bruneval, Phys. Rev. Appl. 1, 024005 (2014).

[93] B. Meyer, Alves, H, D. Hofmann, W. Kriegseis, D. Forster, F. Bertram, J. Christen, A. Hoffmann, M. Straßburg, M. Dworzak, Phys. Status Solidi B 241, 231 (2004).

[94] C. Ton-That, L. Zhu, M. N. Lockrey, M. R. Phillips, B. C. C. Cowie, A. Tadich, L. Thomsen, S. Khachadorian, S. Schlichting, N. Jankowski, A. Hoffmann, Phys. Rev. B 92, 7 (2015).

[95] C. L. Perkins, S. H. Lee, X. N. Li, S. E. Asher, T. J. Coutts, J. Appl. Phys. 97, 7 (2005).

[96] W. R. L. Lambrecht, A. Boonchun, Phys. Rev. B 87, 195207 (2013).

[97] K. K. Kim, H. S. Kim, D. K. Hwang, J. H. Lim, S. J. Park, Appl. Phys. Lett. 83, 63 (2003).

[98] A. Allenic, W. Guo, Y. Chen, M. B. Katz, G. Zhao, Y. Che, Z. Hu, B. Liu, S. B. Zhang, X. Pan, Adv. Mater. 19, 3333 (2007).

[99] P. Li, S.-H. Deng, J. Huang, Appl. Phys. Lett. 99, 111902 (2011).

[100] A. Allenic, W. Guo, Y. Chen, Y. Che, Z. Hu, B. Liu, X. Pan, J. Phys. D: Appl. Phys. 41, 025103 (2007).

[101] X. Pan, W. Guo, Z. Ye, B. Liu, Y. Che, H. He, X. Pan, J. Appl. Phys. 105, 113516 (2009). 


\begin{tabular}{|lllll} 
March 4, $2020 \quad$ 19:49 Defects in Functional Materials $\quad 9 i n \times 6$ in $\quad$ 1st Reading b3851-ch06 page 200 &
\end{tabular}

